\section{Never take a shade again}

Traditionally, in order to provide the optimum in aesthetic composite restorations it is necessary to spend a considerable amount of time taking an accurate shade match. Even then, it is sometimes wrong when the patient gets out of the chair.

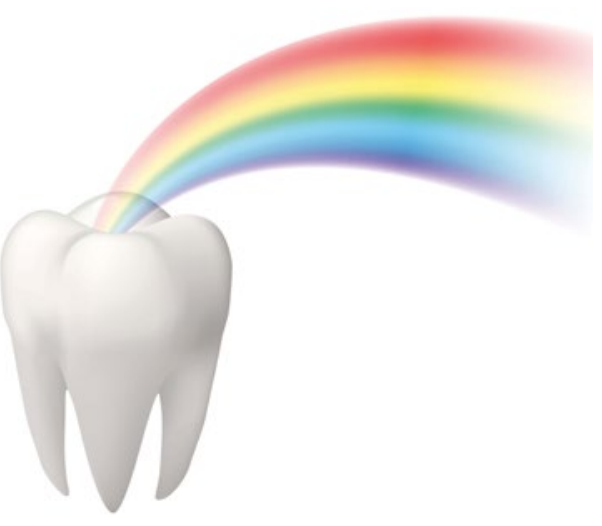

It is also necessary to stock rarely used shades - shades that can go out of date before you have used them up.

Tokuyama have eliminated the cost and inconvenience of both of these problems with the introduction of Omnichroma, the world's first shadeless composite.

Tokuyama’s shadeless Omnichroma combines patented 'structural colour' pearl technology with advanced resin expertise so that just one shadeless Omnichroma and Omnichroma Blocker is all that is needed to replace all 16 Vita shades of any other composite system.

This means that there is no need to shade match ever again because just one pack saves the time and cost of, on average, 20 shade matches. In addition, its white opaque uncured appearance makes it clearly visible when packing and carving, and it becomes invisible when cured.

Quick and easy to adapt into the cavity, it is extremely quick and easy to polish, again saving valuable time.

More information about the complete Tokuyama range, including Omnichroma, is available by contacting your local Trycare Representative, calling 01274885544 or visiting www.trycare.co.uk/omnichroma.

\section{Digital impact on implantology speech}

Professor Cemal Ucer - Specialist Oral Surgeon, clinical lead MSc Programme in Dental Implantology at Salford University and Director of Ucer Education - will be speaking at the Digital Dentistry Society UK Inaugural Conference on 24 May 2019.

His session, entitled 3D digital planning and surgical navigation for safe dental implant treatment, will explore the benefits and principles of computer guided 3D implant planning; the complete digital workflow; immediate loading options using $3 \mathrm{D}$ guided surgical navigation; and innovative new techniques such as the $3 \mathrm{D}$ printed titanium jaw implants for the treatment of severely atrophic jaws.

Professor Ucer will share his extensive knowledge and experience of the reconstruction of jaws from missing single teeth to severely atrophic cases. He will demonstrate how the 3D digital workflow has revolutionised his oral implantology practice and show delegates how to enhance the effectiveness and predictability of their treatment planning and the safety of implant surgery.

For more information on Ucer Education and the PG Cert in Dental Implantology available, visit www.ucer.education or call 01612371842.

\section{Breakthrough for caries management}

Using a specific photoprotein that produces bioluminescence in the presence of free calcium ions, the CALCIVIS system displays a visual map of active demineralisation at the chair side. This enables practitioners and their patients to clearly see the very early signs of caries long before surgical intervention is required.

With definitive evidence of active demineralisation, preventive measures can be implemented to prevent the tooth progressing to the cavitation stages. By identifying free calcium ions so precisely, the CALCIVIS system provides a means of assessing the efficacy of reparative or remineralisation therapies.

For more information, visit www.calcivis.com, call 01316585152 or email at info@ calcivis.com.

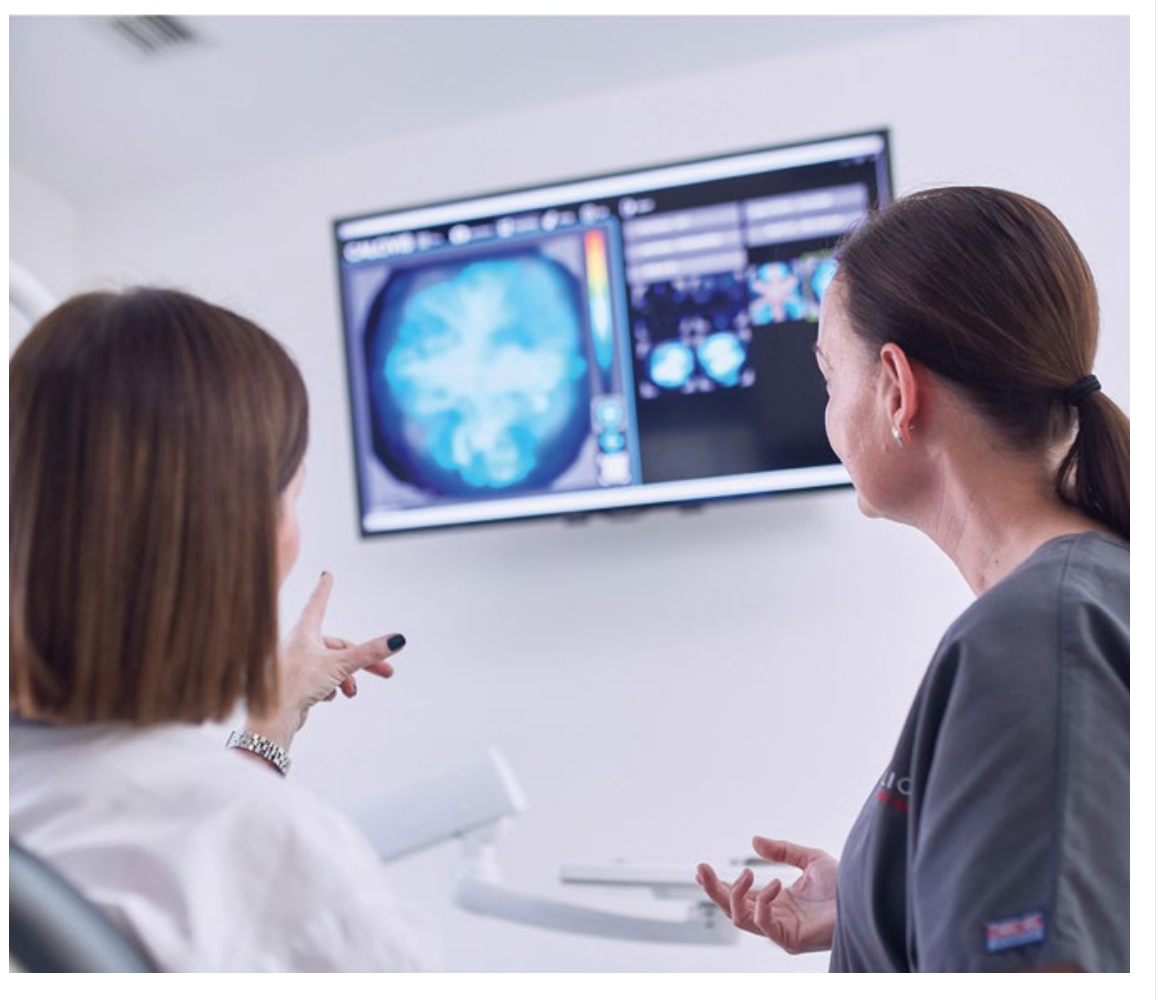

